\title{
ResearchOnline@JCU
}

This is the author-created version of the following work:

Johansson, C.L., van de Leemput, I.A., Depczynski, M., Hoey, A.S., and Bellwood, D.R. (2013) Key herbivores reveal limited functional redundancy on inshore coral reefs. Coral Reefs, 32 (4) pp. 963-972.

Access to this file is available from:

https://researchonline.jcu.edu.au/26865/

Please refer to the original source for the final version of this work:

http://dx.doi.org/10.1007/s00338\%2D013\%2D1044\%2Dy 


\section{Key herbivores reveal limited functional redundancy on inshore}

\section{coral reefs}

C. L. Johansson ${ }^{1,2^{*}}$, I. A. van de Leemput ${ }^{3}$, M. Depczynski ${ }^{4}$, A. S. Hoey ${ }^{2}$ and D. R. Bellwood 2

${ }^{1}$ AIMS@JCU, Australian Institute of Marine Science, and School of Marine and Tropical Biology, James Cook University, Townsville, Queensland 4811, Australia

${ }^{2}$ Australian Research Council Centre of Excellence for Coral Reef Studies and School of Marine and Tropical Biology, James Cook University, Townsville, Queensland 4811, Australia

${ }^{3}$ Aquatic Ecology and Water Quality Management Group, Wageningen University, Wageningen, the Netherlands.

${ }^{4}$ Australian Institute of Marine Science, UWA Oceans Institute, Crawley, Western Australia 6009, Australia

*Corresponding author: charlotte.johansson@my.jcu.edu.au

Keywords: functional groups, herbivores, resilience, functional redundancy, species richness, response diversity 


\section{ABSTRACT}

Marine ecosystems are facing increasing exposure to a range of stressors and declines in critical ecological functions. The likelihood of further loss of functions and resilience is dependent, in part, on the extent of functional redundancy (i.e., the capacity of one species to functionally compensate for the loss of another species) within critical functional groups. We used multiple metrics: species richness, generic richness, abundance and reserve capacity (i.e., the relative number of individuals available to fulfil the function if the numerically dominant species is lost), as indicators to assess the potential functional redundancy of four functional groups of herbivorous fishes (browsers, excavators, grazers and scrapers) in two of the worlds' most intact coral reef ecosystems: the Great Barrier Reef (GBR) and Ningaloo Reef in Western Australia. We found marked variations in potential redundancy among habitats within each reef system and functional groups. Despite negligible fishing of herbivorous fishes, coastal habitats in both reef systems had lower functional redundancy compared to offshore locations for all herbivorous fishes collectively and the four functional groups independently. This pattern was consistent in all four indicators of redundancy. The potential vulnerability of these coastal habitats is highlighted by recent shifts from coral- to macroalgal dominance on several coastal reefs of the GBR. Our approach provides a simple yet revealing evaluation of potential functional redundancy. Moreover, it highlights the spatial variation in potential vulnerability and resilience of reef systems.

\section{INTRODUCTION}

Many of the worlds' ecosystems are in serious decline (Jackson et al. 2001; Walther et al. 2002; Hughes et al. 2003). The combined effects of climate change and anthropogenic disturbances have led to declines in the biodiversity, productivity and dynamics of ecosystems, 
with shifts to alternate assemblages of species becoming increasingly common (Scheffer et al. 2001). Coral reefs are one of the world's most productive and biologically diverse ecosystems, yet they are also one of the most threatened (Walther et al. 2002). Moreover, predicted increases in the diversity, frequency and severity of disturbances affecting coral reefs (Sheppard 2003; Donner et al. 2005) are raising concerns over their long-term persistence. As coral reefs are increasingly exposed to multiple stressors, their ability to absorb shocks, resist change and/or reassemble after disturbances (i.e., resilience, Holling 1973) may gradually erode (Hughes et al. 2005). There is, however, high spatial variability in the resilience of coral reefs. Reefs in the inner Seychelles have displayed varying responses to large-scale coral mortality with some being overgrown by fleshy macroalgae while others have returned to coral-dominance (Graham et al. 2006; Chong-Seng et al. 2012). Similarly on the Great Barrier Reef (GBR), one of the world's most intact coral reef systems, several inshore reefs have transitioned from coral- to macroalgal-dominance (Done 1992; Diaz-Pulido et al. 2009; Cheal et al. 2010; Hughes et al. 2010), yet other reefs, especially those further offshore have resisted change. Determining the factors that underpin this spatial variation in resilience is key to understanding the dynamics of these systems.

The ability of reefs to cope with environmental disturbances is strongly dependent on the species present, their functional roles, and their response to perturbations (Folke et al. 2004). A reduced number of species and functions, or a lack of variation in the responses of species to disturbance, can push a system closer to an ecosystem threshold, and reduce the chances of recovery (Walker et al. 1999). Herbivorous fishes perform a critical role on coral reefs (Bellwood et al. 2004; Burkepile and Hay 2006). Collectively, herbivorous fishes control the biomass and distribution of benthic algae, minimise coral-algal competition, provide suitable substrata for coral settlement and, in doing so, promote the recovery of coral communities following disturbance (Steneck 1988; Bellwood et al. 2004; Hughes et al. 2007). 
There is, however, considerable variation in the functional impact among herbivorous species with four distinct functional groups (browsers, excavators, grazers and scrapers) performing different and complimentary roles: excavators erode dead coral skeletons; scrapers remove turf algae and sediment leaving surfaces clear for settlement; and grazers/detritivores (hereafter termed grazers) reduce turf algal biomass and/or associated detritus with no disturbance to the underlying reef surface (Green and Bellwood 2009; Burkepile and Hay 2010, 2011; Bellwood et al. 2012). While excavators, grazers and scrapers all harvest the epilithic algal matrix, browsers are the species capable of reducing the biomass of large algal turfs or fleshy macroalgae (Bellwood et al. 2006; Hoey and Bellwood 2009).

The importance of the four functional groups for reef ecosystem health is apparent. However, their ability to support ecosystem functions now, and into the future, depends on the level of functional redundancy within each group (i.e., the capacity of one species to functionally compensate for the loss of another species: Bellwood et al. 2004; Nyström et al. 2008). Functional redundancy not only requires a high diversity of functionally similar species but also that species within a functional group must have dissimilar responses to ecosystem stressors (i.e., response diversity), preventing all species within a function being lost as a result of a disturbance (Elmqvist et al. 2003; Nyström 2006; Thibaut et al. 2012). Response diversity often reflects the taxonomic or phylogenetic diversity of the taxa that make up a functional group (Elmqvist et al. 2003), where slightly different functional traits make some genera more or less susceptible to a given disturbance (Thibaut et al. 2012). For herbivorous fishes, there have been several studies that show differential susceptibility to disturbance, with greatest variability among rather than within genera (e.g., Pratchett et al. 2011; Bellwood et al. 2012). Hence, species richness and generic richness may provide an indication of the number of functionally similar species and the level of potential response diversity available within a 
functional group, respectively. However, neither of these metrics incorporates a measure of species abundance.

To maintain and secure ecosystem functions, it is essential that individuals supporting critical functional roles are present in sufficient numbers to effectively deliver their functions (Rosenfeld 2002; Hoey and Bellwood 2009; Bellwood et al. 2012). Collectively the abundance of all species within a functional group provides an indication of the intensity or magnitude of that function and subsequently the vulnerability of the system to disturbances. As the overall abundance of species within a functional group declines the intensity of that function correspondingly weakens, potentially reducing the resilience of the system and increasing its sensitivity to ecosystem shifts. The resilience of a system is also influenced by the relative abundance of species within a functional group, in particular the proportion of numerically non-dominant species, herein termed reserve capacity, i.e., the relative number (proportion) of individuals available to fulfil the function if the numerically dominant species is lost). If two species are equally abundant they may be clear substitutes. However, if one is rare, its capacity to effectively take over a functional role may be limited (Nyström et al. 2008). Each of these metrics: species richness, generic richness, and reserve capacity, thus provides a slightly different perspective on how likely it is that species are able to replace each other (i.e., functional redundancy). The three metrics act as potential indicators of functional redundancy, and, together with abundance, provide an indication of the vulnerability of a functional group to disturbances.

Using these four metrics (species richness, generic richness, abundance and reserve capacity) we investigate spatial patterns of potential functional redundancy in herbivorous fish assemblages in two of the world's most intact coral reef ecosystems, the GBR and Ningaloo Reef, Western Australia. Specifically, we examine potential functional redundancy in each of the four functional groups of herbivorous coral reef fish across a range of habitats spanning the 
continental shelf in each system. These two reef ecosystems are well managed and are likely to have relatively intact herbivorous fish assemblages; there is no recreational or commercial fishery for herbivorous fishes. We therefore hypothesise that these reef systems should exhibit exceptionally high redundancy in all four metrics, although significant spatial variation within each system might be critical.

\section{METHODS}

Spatial patterns of potential functional redundancy were quantified/estimated from visual censuses of herbivorous fish communities on the GBR on Australia's east coast, and Ningaloo Reef, Western Australia (Fig. 1). All nominally herbivorous fishes (Acanthuridae, Ephippidae, Kyphosidae, Labridae [parrotfishes], Pomacanthidae [pygmy angelfishes], and Siganidae) greater than $10 \mathrm{~cm}$ total length were censused in a range of habitats that spanned the continental shelf in each system. A $10 \mathrm{~cm}$ cut-off was used to ensure no recently recruited individuals were sampled, to ensure only individuals with a fully-developed herbivorous function were included, and to minimise problems with the cryptic behaviour of smaller individuals. On the GBR the continental shelf is approximately $110 \mathrm{~km}$ wide at the studiy location, whereas on Ningaloo it is just 0.2 to $7 \mathrm{~km}$ wide (average $=2.5 \mathrm{~km}$; Cassata and Collins 2008). On the GBR censuses were conducted in the Townsville region in 2005, with eight 10 min x 5 m timed swim transects (ca. $590 \mathrm{~m}^{2}$ ) conducted in each of eleven cross-shelf habitats (i.e., four habitats [back reef, reef flat, crest and slope] on mid-, and outer-shelf reefs but only three on inshore reefs, due to the lack of a distinct reef crests in these locations; see Wismer et al. 2009). On Ningaloo Reef, ten $250 \mathrm{~m}$ x $5 \mathrm{~m}$ transects $\left(1250 \mathrm{~m}^{2}\right)$ were conducted in each of three cross-shelf habitats (reef slope, back reef and lagoon representing outer, mid and inner reef location) in 2009 to 2010 . Fish were categorised into four functional groups: browsers, 
excavators, grazers/detritivores (referred to herein as grazers) and scrapers (following Hoey and Bellwood 2011). The number of observed fish, species, and genera were recorded for each functional group for each transect within each habitat at each location (GBR and Ningaloo Reef). Then, mean abundance (ind. $100 \mathrm{~m}^{-2}$ ), mean species richness, and mean genera richness were calculated for each habitat at each location. Differences in transect areas preclude direct comparisons of species or genera richness among locations.

To assess reserve capacity, the most abundant species in each functional group on each transect was identified as the numerically dominant species. Reserve capacity per transect was calculated as the proportion of fish that do not belong to this dominant species. The mean reserve capacity of each functional group in each habitat $(\overline{R C})$ was determined by the weighted average of the reserve capacity values per transect (e.g. weighted to fish abundance), which is simply the same as the proportion of all fish on all transects that do not belong to the dominant species: $\overline{R C}=\frac{\sum_{i=1}^{n}\left(R C_{i} A_{i}\right)}{\sum_{i=1}^{n} A_{i}}=\frac{\sum_{i=1}^{n}\left(\left(\frac{A_{i}-D_{i}}{A_{i}}\right) A_{i}\right)}{\sum_{i=1}^{n} A_{i}}=\frac{\sum_{i=1}^{n}\left(A_{i}-D_{i}\right)}{\sum_{i=1}^{n} A_{i}}$

where $\mathrm{A}_{\mathrm{i}}$ is the total fish abundance on transect $i, D_{i}$ is the abundance of the numerically dominant species on transect $i$, and $n$ is the total number of transects within each habitat. The weighted average was used, so that a reserve capacity value based on a transect with high total fish abundance is given a higher weight than a reserve capacity value based on a transect with low total fish abundance. Reserve capacity (rather than evenness) was used to emphasise the relative contribution of the numerically dominant species. Reserve capacity is more appropriate than other indices (e.g., evenness) as it quantifies the relative contribution of all numerically non-dominant species collectively rather than the relative contribution of individual species. 
Among habitat variation in potential functional redundancy within each functional group and for all herbivorous fishes collectively was explored graphically for both reef systems. For graphical reasons, species richness was plotted against generic richness, and abundance was plotted against reserve capacity. A habitat with high species richness, generic richness, abundance and reserve capacity was considered to have higher potential functional redundancy.

Among habitat variation in mean species and generic richness and mean reserve capacity of each functional group in each reef system were analysed using generalised linear models. Species and generic richness are both discrete variables and were analysed using a Poisson regression. Because reserve capacity levels are proportions (between 0 and 1), they were analysed using logistic regression (Dalgaard 2008). The total abundance of fish was used as a weight for the logistic regression model, to account for the number of observations on each transect. All regression models were performed in $\mathrm{R}$ using the $\mathrm{glm}$ function(R Core Team 2012). Variation in mean abundance of each functional group was compared among habitats within each reef system using an ANOVA. Abundance data were examined for normality and homoscedasticity using analysis of residuals, and no transformation was needed.

\section{RESULTS}

Overall species richness and generic richness varied among functional groups, with grazers having the most species and genera on both Ningaloo Reef and the GBR (Electronic Supplemental Material, ESM Table S1). On Ningaloo Reef, a total of 44 species of herbivorous fishes were recorded, with 19 grazing, 13 scraping, 10 browsing and 2 excavating species. Grazing species belonged to five genera, scrapers to two, browsers to three, while excavators belonged to a single genus. On the GBR, 57 herbivorous fish species were recorded, consisting 
of 24 grazing, 18 scraping, 10 browsing, and five excavating species belonging to six, two, three and three genera respectively.

There were remarkably consistent cross-shelf patterns on both the GBR and Ningaloo Reef. Species richness, generic richness, abundance and reserve capacity of the four herbivore functional groups were all generally lower within inshore or coastal habitats compared to habitats further offshore (Figs. 2 and 3). These patterns were even more pronounced for herbivorous fishes as a whole (Fig. 4). On Ningaloo Reef the inshore habitat had significantly fewer species of browsers, grazers and scrapers than the offshore habitats (ESM Table S2). The number of excavating species was also lowest on the inshore Ningaloo Reef habitat, but only differed significantly from the mid-shelf habitat (Fig. 2c). Similarly, inshore habitats on the GBR generally had fewer species of scrapers and grazers than mid and outer-shelf habitats (scrapers: $\mathrm{p}<0.01$ for all pairwise comparisons; grazers: $\mathrm{p}<0.05$ for 22 of 24 comparisons; see ESM Tables S3 and S4 for further details). Even within the species depauperate browsing and excavating groups the inner-shelf GBR habitats generally had fewer species than the midand outer-shelf habitats (Fig. 2 b, d; ESM Table S4). Generic richness displayed broadly similar patterns with inshore habitats having fewer genera than the offshore habitats (Fig. 2), however, the limited number of genera within each functional group reduced the ability to detect significant differences. On Ningaloo Reef the inshore habitat had significantly fewer genera of grazers and browsers than the offshore habitats. Similarly, the number of genera within each of the functional groups was consistently lowest within the inshore habitats on the GBR. With the exception of grazers ( $\mathrm{p}<0.05$ for 16 of 24 comparisons), however, relatively few of these among-habitat differences were significant (ESM Table S5).

Abundance of fishes within each functional group varied significantly among habitats on both the GBR and Ningaloo Reef (Fig. 3; ESM Tables S6-S7). Abundances of each functional group were generally lowest on inshore habitats, however, high within-habitat 
variability limited the number of statistically significant differences detected (ESM Tables S6 and S8). Reserve capacity was low $(<50 \%)$ for the species depauperate browsers and excavators across most habitats in both reef systems (Fig. 3a-d). This was especially pronounced on inshore habitats (browsers: 0-33\%; excavators: 0-6 \%) indicating the processes delivered by these groups are dominated by a single species. Reserve capacity was more varied among the grazers and scrapers, with inshore habitats having significantly lower values than most offshore habitats on Ningaloo Reef and the GBR (Fig. 3e-h; ESM Tables S9-S11).

\section{DISCUSSION}

Coral reefs, like many of the world's ecosystems, are in decline (Walther et al. 2002; Bellwood et al. 2004). Given the predicted increases in the frequency and severity of disturbances affecting coral reefs, the ability of reefs to persist into the future will depend, at least in part, on the level of functional redundancy within critical ecosystem process such as herbivory. Using four simple metrics that are inherent in most datasets (i.e., species richness, generic richness, abundance and reserve capacity) we estimated spatial variation in potential functional redundancy of herbivorous fishes on two of the world's most intact reefs systems; the GBR and Ningaloo Reef. Our results revealed remarkably consistent cross-shelf patterns in all four metrics for herbivorous fishes collectively, and the four functional groups (i.e., browsers, excavators, grazers and scrapers) independently. Strikingly, both potential functional redundancy and the intensity of each function were markedly reduced in coastal habitats of both reef systems suggesting that these habitats may be the most vulnerable to future disturbances. Coastal habitats consistently had the lowest species and generic richness, abundance and reserve capacity within each of the functional groups. The low levels of potential functional redundancy found among herbivorous fishes at these inshore locations 
indicate that the processes supported by these functional groups are not only dependent on a limited number of closely related species, but are also likely to have a limited ability to respond to disturbances. Indeed, the vulnerability of these reefs is highlighted by the transition of several inshore reefs on the GBR to macroalgal-dominance following disturbance (Done 1992; Done et al. 2007; Diaz-Pulido et al. 2009; Cheal et al. 2010; Hughes et al. 2010).

Species richness has been widely used as a proxy for functional redundancy across a range of ecosystems (Jarvinen 1982; Fraser and Currie 1996; Gotelli and Colwell 2001; Hope et al. 2003). While it provides an indication of the number of functionally similar species, species richness does not consider how the component species may respond to disturbances. Incorporating generic richness provides an additional dimension of redundancy by including a measure of potential response diversity (e.g., Pratchett et al. 2011). Collectively, species richness and generic richness provide valuable information on the number of species contributing to a particular function and their potential responses to a disturbance event. However, they do not consider the relative contribution or importance of each species in performing the function. The number of individuals within a species or functional group can be reported either as absolute abundance, providing an indication of the intensity of the process, or as relative abundance of all non-numerically dominant species to the numerically dominant species (i.e., reserve capacity). Ecosystem processes with a strong numerical dominance of one species (i.e., keystone species) can be exceptionally sensitive to disturbances (Steneck et al. 2011). It is the abundance of species remaining, if the dominant species is lost, that might best indicate an abundance-based capacity for redundancy. If the abundance of non-dominant species far exceeds that of the dominant species, redundancy is likely to be high. In contrast, where a process is supported by just one or two species (Hoey and Bellwood 2009; Bellwood et al. 2012) the loss of just one species may equate to the local collapse of a crucial ecosystem process. 
These four metrics; species richness, generic richness, abundance and reserve capacity, provide different, yet complementary, measures of functional redundancy. The addition of reserve capacity, in particular, provides key information on the potential vulnerability of a location. Reserve capacity identifies functional groups that may appear resilient as a result of high abundances, but which may have a reduced capacity to cope with ecosystem disturbances due to the dominance of one species. In this situation high abundance of a single species should be recognised as a potential vulnerability (Steneck et al. 2011). Previous studies have identified vulnerable habitats or functional groups in coral reef ecosystems (Wilson et al. 2006; Bellwood et al. 2012). Studies on the GBR, for example, using species richness and abundance have inferred limited functional redundancy of herbivorous reef fishes on inshore reefs (Hoey and Bellwood 2008; Cheal et al. 2012a, 2012b). Our results support and expand these findings to show that inshore reefs on both Ningaloo Reef and the GBR are likely to have more vulnerable herbivorous fish assemblages compared to offshore habitats or reefs, in terms of not only species richness and abundance but also generic richness and reserve capacity.

Despite the congruence seen in the four metrics on the GBR and on Ningaloo Reef this pattern may not apply elsewhere. Human impacted reefs, in particular, often lose specific genera relatively quickly (e.g., Bolbometopon, Cetoscarus, Naso), while others may increase in abundance (e.g., Scarus) (Hoey and Bellwood 2009; Bellwood et al. 2012). Thus one may anticipate impacted reefs to have a markedly different profile among the four metrics when compared to more intact reefs; impacted reefs having lower generic richness and reserve capacity and limited changes to species richness and total abundances. Indeed, these metrics may be sensitive to differences in the nature of impacts (direct human vs environmental cf. Mouillot et al. 2013) and may reflect different types of vulnerability on coral reefs. 
Our study identifies coastal habitats or reefs as areas of heightened vulnerability on both the GBR and Ningaloo Reef. Compared to habitats further offshore, coastal habitats displayed lower species and generic richness, lower abundance and reserve capacity across browsing, excavating, grazing and scraping fishes, and all herbivorous fishes collectively. Moreover, these critical ecosystem processes were all dominated by just one species within these coastal habitats. This raises the question why coastal reefs, in two protected reef ecosystems, appear to be so vulnerable. Interestingly, the coastal habitats on Ningaloo Reef and the GBR both exhibit fish assemblages with low functional redundancy and benthic communities with higher macroalgal cover compared to non-coastal habitats (Wismer et al. 2009; Johansson et al. 2010). On Ningaloo Reef, minimal coastal development suggests that these characteristics of inshore habitats are unlikely to be a result of direct anthropogenic impacts, and may be a natural feature of this system (Johansson et al. 2010). In contrast, inner reefs on the GBR have a history of compromised water quality due to terrestrial runoff (McCook 1996, 1999; De'ath and Fabricius 2010; Schaffelke et al. 2012) and these habitats with reduced water clarity appear to have a lower abundance of herbivorous fishes compared to off-shore habitats (Cheal et al. 2012b). The extent to which low herbivorous fish abundances are a natural feature of coastal GBR reefs or a result of anthropogenic stressors remains unclear. However, due to the low abundances and low levels of functional redundancy among herbivorous fishes, the capacity of coastal reef communities to control algal outbreaks on Ningaloo Reef and the GBR appears to be limited.

Using four metrics to examine potential functional redundancy, in four key functional groups, across two coral reef systems: Ningaloo Reef and the GBR, revealed remarkable congruence. In all metrics, groups, and systems, coastal habitats had less functional redundancy compared to non-coastal reefs, revealing considerable vulnerability to future disturbance. Coastal reef habitats on both Ningaloo Reef and the GBR may therefore have a reduced 
capacity to cope with change or to deal with macroalgal outbreaks. We suggest that our approach, using four simple metrics that are inherent in most datasets; species richness, generic richness, abundance and reserve capacity, can act as a tool for estimating potential functional redundancy. Furthermore, in highlighting likely vulnerability for both functional groups and habitats, this approach offers a focus for areas of consideration when planning future management and conservation efforts.

\section{ACKNOWLEDGEMENTS}

We thank: S. Wilson, T. Holmes, P. Tinkler, T. Mannering, C. Fulton, A. Barnett and C. Birrell for field assistance; J. Tanner, C. Goatley, R. Lawton, and two anonymous reviewers for helpful comments on the manuscript; K. Nash and R. Jones for statistical advice; the Australian Institute of Marine Science and Department of Environment and Conservation for logistical support; AIMS@JCU (CLJ), the Australian Research Council (DRB, ASH), Ecoshape Building with Nature (IvdL), and the Western Australian Marine Science Institute (WAMSI) (MD) for financial support. 


\section{LITERATURE CITED}

Bellwood DR, Hughes TP, Hoey AS (2006) Sleeping functional group drives coral reef recovery. Curr Biol 16:2434-2439

Bellwood DR, Hoey AS, Hughes TP (2012) Human activity selectively impacts the ecosystem roles of parrotfishes on coral reefs. Proc R Soc B Biol Sci 279:1621-1629

Bellwood DR, Hughes TP, Folke C, Nyström M (2004) Confronting the coral reef crisis. Nature 429:827-833

Burkepile DE, Hay ME (2006) Herbivore vs. nutrient control of marine primary producers: context-dependent effects. Ecology 87:3128-3139

Burkepile DE, Hay ME (2010) Impact of herbivore identity on algal succession and coral growth on a Caribbean reef. PLoS One 5:e8963

Burkepile DE, Hay ME (2011) Feeding complementarity versus redundancy among herbivorous fishes on a Caribbean reef. Coral Reefs 30:351-362

Cassata L, Collins LB (2008) Coral reef communities, habitats, and substrates in and near sanctuary zones of Ningaloo Marine Park. J Coast Res 24:139-151

Cheal A, Emslie M, Miller I, Sweatman H (2012a) The distribution of herbivorous fishes on the Great Barrier Reef. Mar Biol 159:1143-1154

Cheal AJ, Emslie M, MacNeil MA, Miller I, Sweatman H (2012b) Spatial variation in the functional characteristics of herbivorous fish communities and the resilience of coral reefs. Ecol Appl [doi: 10.1890/11-2253.1]

Cheal AJ, MacNeil MA, Cripps E, Emslie MJ, Jonker M, Schaffelke B, Sweatman H (2010) Coral-macroalgal phase shifts or reef resilience: links with diversity and functional roles of herbivorous fishes on the Great Barrier Reef. Coral Reefs 29:1005-1015

Chong-Seng KM, Mannering TD, Pratchett MS, Bellwood DR, Graham NAJ (2012) The influence of coral reef benthic condition on associated fish assemblages. PLoS One 7:e42167

Dalgaard P (2008) Introductory Statistics with R. In: Chambers JM, Hand D, Hardle W (eds) Springer, New York

De'ath G, Fabricius K (2010) Water quality as a regional driver of coral biodiversity and macroalgae on the Great Barrier Reef. Ecol Appl 20:840-850

Diaz-Pulido G, McCook LJ, Dove S, Berkelmans R, Roff G, Kline DI, Weeks S, Evans RD, Williamson DH, Hoegh-Guldberg O (2009) Doom and boom on a resilient reef: climate change, algal overgrowth and coral recovery. PLoS One 4:e5239

Done TJ (1992) Phase-shifts in coral-reef communities and their ecological significance. Hydrobiologia 247:121-132

Done T, Turak E, Wakeford M, DeVantier L, McDonald A, Fisk D (2007) Decadal changes in turbid-water coral communities at Pandora Reef: loss of resilience or too soon to tell? Coral Reefs 26:789-805

Donner SD, Skirving WJ, Little CM, Oppenheimer M, Hoegh-Guldberg O (2005) Global assessment of coral bleaching and required rates of adaptation under climate change. Global Change Biol 11:2251-2265

Elmqvist T, Folke C, Nyström M, Peterson G, Bengtsson J, Walker B, Norberg J (2003) Response diversity, ecosystem change, and resilience. Front Ecol Environ 1:488-494

Folke C, Carpenter S, Walker B, Scheffer M, Elmqvist T, Gunderson L, Holling CS (2004) Regime shifts, resilience, and biodiversity in ecosystem management. Annual Review of Ecology, Evolution and Systematics 35:557-581

Fraser RH, Currie DJ (1996) The species richness-energy hypothesis in a system where historical factors are thought to prevail: coral reefs. Am Nat 148:138-159 
Gotelli NJ, Colwell RK (2001) Quantifying biodiversity: procedures and pitfalls in the measurement and comparison of species richness. Ecol Lett 4:379-391

Graham NAJ, Wilson SK, Simon J, Polunin NVC, Bijoux JP, Robinson J (2006) Dynamic fragility of oceanic coral reef ecosystems. Proc Natl Acad Sci USA 103:8425-8429

Green AL, Bellwood DR (2009) Monitoring functional groups of herbivorous reef fishes as indicators of coral reef resilience - a practical guide for coral reef managers in the Asia Pacific region. IUCN working group on climate change and coral reefs, IUCN, Gland, Switzerland

Hoey AS, Bellwood DR (2008) Cross-shelf variation in the role of parrotfishes on the Great Barrier Reef. Coral Reefs 27:37-47

Hoey AS, Bellwood DR (2009) Limited functional redundancy in a high diversity system: single species dominates key ecological process on coral reefs. Ecosystems 12:13161328

Hoey AS, Bellwood DR (2011) Suppression of herbivory by macroalgal density: a critical feedback on coral reefs? Ecol Lett 14:267-273

Holling CS (1973) Resilience and stability of ecological systems. Annu Rev Ecol Syst 4:1-23

Hope D, Gries C, Zhu W, Fagan WF, Redman CL, Grimm NB, Nelson AL, Martin C, Kinzig A (2003) Socioeconomics drive urban plant diversity. Proc Natl Acad Sci USA 100:8788-8792

Hughes T, Bellwood D, Folke C, Steneck RS, Wilson J (2005) New paradigms for supporting the resilience of marine ecosystems. Trends Ecol Evol 20:380-386

Hughes TP, Graham NAJ, Jackson JBC, Mumby PJ, Steneck RS (2010) Rising to the challenge of sustaining coral reef resilience. Trends Ecol Evol 25:633-642

Hughes TP, Rodrigues MJ, Bellwood DR, Ceccarelli D, Hoegh-Guldberg O, McCook L, Moltschaniwskyj N, Pratchett MS, Steneck RS, Willis B (2007) Phase shifts, herbivory, and the resilience of coral reefs to climate change. Curr Biol 17:360-365

Hughes TP, Baird AH, Bellwood DR, Card M, Connolly SR, Folke C, Grosberg R, HoeghGuldberg O, Jackson JBC, Kleypas J, Lough JM, Marshall P, Nyström M, Palumbi SR, Pandolfi JM, Rosen B, Roughgarden J (2003) Climate change, human impacts, and the resilience of coral reefs. Science 301:929-933

Jackson JBC, Kirby MX, Berger WH, Bjorndal KA, Botsford LW, Bourque BJ, Bradbury RH, Cooke R, Erlandson J, Estes JA, Hughes TP, Kidwell S, Lange CB, Lenihan HS, Pandolfi JM, Peterson CH, Steneck RS, Tegner MJ, Warner RR (2001) Historical overfishing and the recent collapse of coastal ecosystems. Science 293:629-637

Jarvinen O (1982) Species-to-genus ratios in biogeography: a historical note. J Biogeogr 9:363-370

Johansson CL, Bellwood DR, Depczynski M (2010) Sea urchins, macroalgae and coral reef decline: a functional evaluation of an intact reef system, Ningaloo, Western Australia. Mar Ecol Prog Ser 414:65-74

McCook LJ (1996) Effects of herbivores and water quality on Sargassum distribution on the central Great Barrier Reef: cross-shelf transplants. Mar Ecol Prog Ser 139:179-192

McCook LJ (1999) Macroalgae, nutrients and phase shifts on coral reefs: scientific issues and management consequences for the Great Barrier Reef. Coral Reefs 18:357-367

Mouillot D, Graham NAJ, Villiger S, Mason NWH, Bellwood DR (2013) A functional approach reveals community responses to disturbances. Trends Ecol Evol [doi:10.1016/j.tree.2012.10.004]

Nyström M (2006) Redundancy and response diversity of functional groups: implications for the resilience of coral reefs. Ambio 35:30-35

Nyström M, Graham NAJ, Lokrantz J, Norström AV (2008) Capturing the cornerstones of coral reef resilience: linking theory to practice. Coral Reefs 27:795-809 
Pratchett MS, Hoey AS, Wilson SK, Messmer V, Graham NAJ (2011) Changes in biodiversity and functioning of reef fish assemblages following coral bleaching and coral loss. Diversity 3:424-452

R Development Core Team (2012). R: A language and environment for statistical computing. R Foundation for Statistical Computing, Vienna, Austria. ISBN 3-900051-07-0, URL http://www.R-project.org/

Rosenfeld JS (2002) Functional redundancy in ecology and conservation. Oikos 98:156-162

Schaffelke B, Carleton J, Skuza M, Zagorskis I, Furnas MJ (2012) Water quality in the inshore Great Barrier Reef lagoon: implications for long-term monitoring and management. Mar Pollut Bull 65:249-260

Scheffer M, Carpenter S, Foley JA, Folke C, Walker B (2001) Catastrophic shifts in ecosystems. Nature 413:591-596

Sheppard CRC (2003) Predicted recurrences of mass coral mortality in the Indian Ocean. Nature 425:294-297

Steneck RS (1988) Herbivory on coral reefs: a synthesis. Proc 6th Int Coral Reef Symp 1:3749

Steneck RS, Hughes TP, Cinner JE, Adger WN, Arnold SN, Berkes F, Boudreau SA, Brown K, Folke C, Gunderson L, Olsson P, Scheffer M, Stephenson E, Walker B, Wilson J, Worm B (2011) Creation of a gilded trap by the high economic value of the Maine lobster fishery. Conserv Biol 25:904-912

Thibaut LM, Connolly SR, Sweatman HPA (2012) Diversity and stability of herbivorous fishes on coral reefs. Ecology 93:891-901

Walker B, Kinzig A, Langridge J (1999) Plant attribute diversity, resilience, and ecosystem function: the nature and significance of dominant and minor species. Ecosystems 2:95-113

Walther GR, Post E, Convey P, Menzel A, Parmesan C, Beebee TJC, Fromentin JM, HoeghGuldberg O, Bairlein F (2002) Ecological responses to recent climate change. Nature 416:389-395

Wilson SK, Graham NAJ, Pratchett MS, Jones GP, Polunin NVC (2006) Multiple disturbances and the global degradation of coral reefs: are reef fishes at risk or resilient? Global Change Biol 12:2220-2234

Wismer S, Hoey AS, Bellwood DR (2009) Cross-shelf benthic community structure on the Great Barrier Reef: relationships between macroalgal cover and herbivore biomass. Mar Ecol Prog Ser 376:45-54 


\section{FIGURES LEGENDS}

Fig. 1. Geographic location of Ningaloo Reef, Western Australia and the Great Barrier Reef off Australia's east coast. Study sites on Ningaloo Reef (black circles) and the Great Barrier Reef (black triangles) are shown. Grey boxes on Ningaloo Reef represents protected sanctuary zones. 


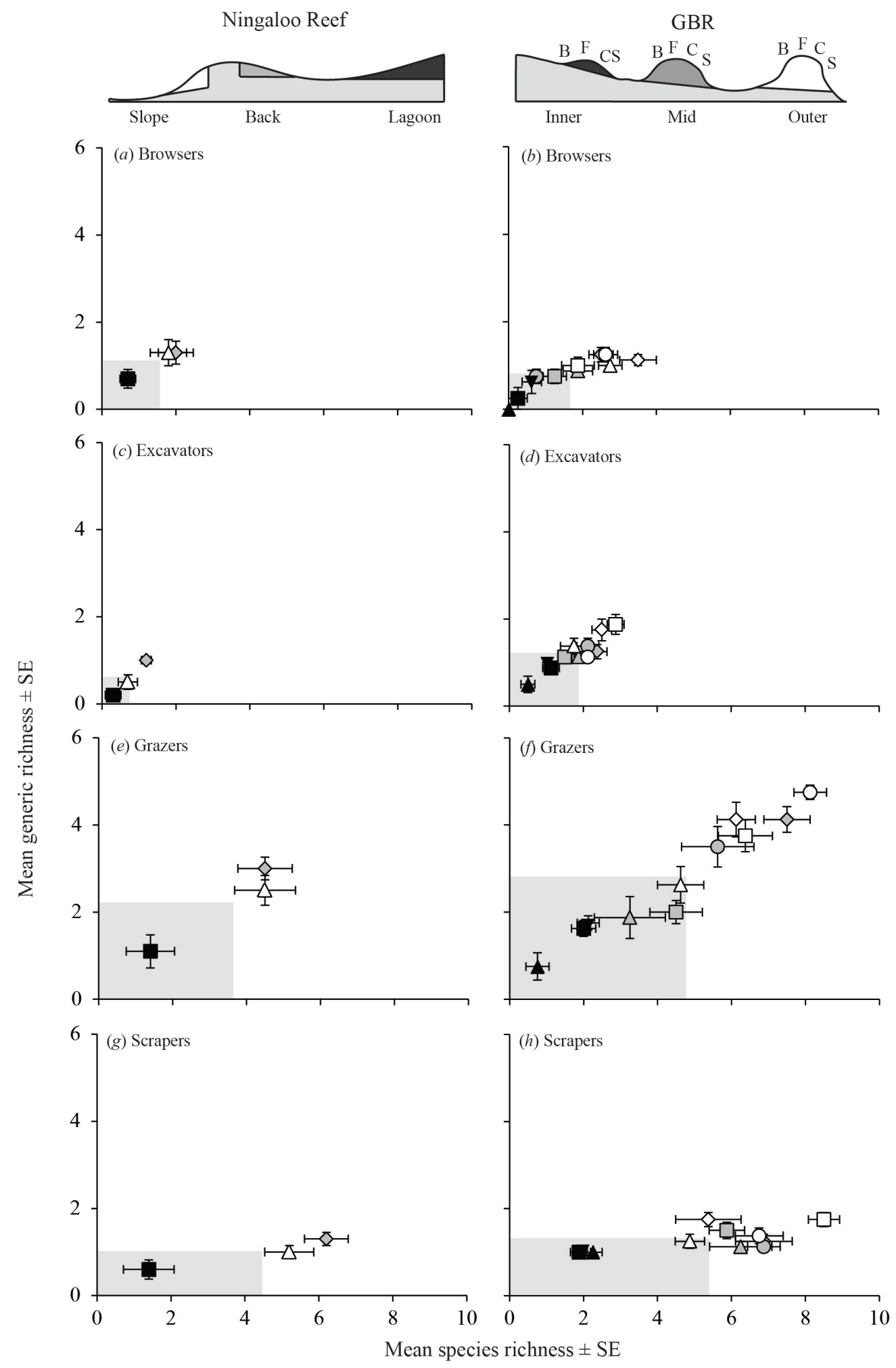

Fig. 2. Mean species richness and mean generic richness per habitat \pm SE for four functional groups of roving herbivorous fish; $(a, b)$ browsers, $(c, d)$ excavators, $(e, f)$ grazers and $(g, h)$ scrapers, in different habitats within two reef ecosystems. Means are based on eight $590 \mathrm{~m}^{2}$ transects on the GBR and ten $1250 \mathrm{~m}^{2}$ transects on Ningaloo. For Ningaloo Reef letters 
represent lagoon (L), back reef (B) and reef slope (S). Letters and symbols for the GBR represent different habitats on the shelf locations: back (B) ( $\mathbf{\square})$, flat $(\mathrm{F})(\mathbf{\Delta})$, crest $(\mathrm{C})(\boldsymbol{\nabla})$ and

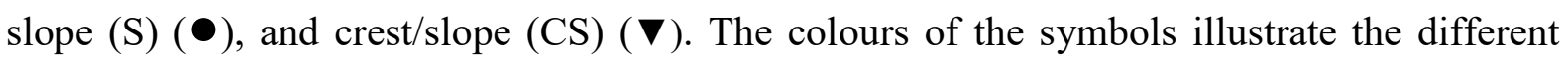
habitats (Ningaloo Reef) /shelf locations (GBR). The grey zones represent the species richness and generic richness below average for each functional group. 


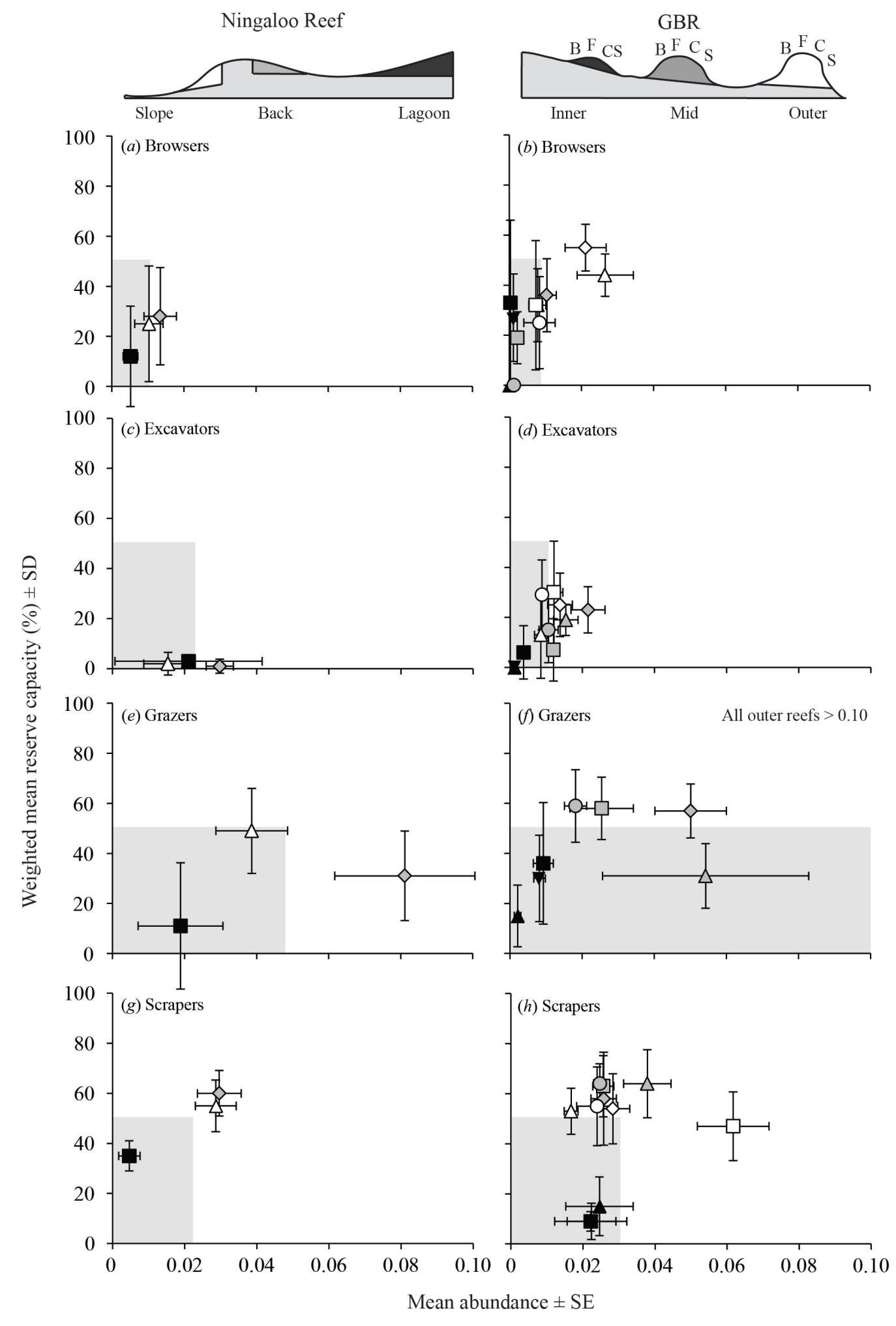

Fig. 3. Mean abundance (individuals $100 \mathrm{~m}^{-2}$ ) \pm SE and weighted mean reserve capacity (in \%) (i.e., relative abundance of all non-numerically dominant species to the total fish abundance) \pm SD for four functional groups of roving herbivorous fish; (a, b) browsers, (c, d) excavators, (e, f) grazers and (g, h) scrapers, in different habitats within two reef ecosystems, Ningaloo Reef 
and the GBR. Symbols and shading follow Fig. 2. The grey zones represent abundance below average, and reserve capacity below $50 \%$, indicating dominance by one species. Grazers on outer reefs have abundances greater than 20 individuals per $100 \mathrm{~m}^{2}$ (see Fig. S1 in ESM for full figure).

Fig. 4. Mean species richness and mean generic richness \pm SE for the four functional groups of roving herbivorous fish combined; in different habitats within two reef ecosystems (a) Ningaloo Reef and (b) Great Barrier Reef(GBR). And mean abundance (in number of observed individuals per $100 \mathrm{~m}^{2}$ ) $\pm \mathrm{SE}$ and weighted mean reserve capacity (in \%) (i.e., relative abundance of all non-numerically dominant species to the total fish abundance) \pm SD for the four functional groups of roving herbivorous fish combined; in different habitats within two reef ecosystems (c) Ningaloo Reef and (d) the GBR. Symbols and shading follow Fig. 2 and 3. 